\title{
A EVOLUÇÃO DA MATRIZ CURRICULAR DO CURSO DE MATEMÁTICA DA UNIVERSIDADE ESTADUAL DO CEARÁ E A FORMAÇÃO DO PROFESSOR
}

\section{THE EVOLUTION OF THE CURRICULUM MATRIX OF THE MATHEMATICS COURSE OF THE CEARÁ STATE UNIVERSITY AND THE TRAINING OF THE TEACHER}

\author{
Diego de Freitas Lira \\ Universidade Federal Rural do Semi-Árido - UFERSA \\ João Victor Lima Fernandes ${ }^{2}$ \\ Secretaria de Educação do Ceará - SEDUC/CE
}

\begin{abstract}
Resumo
O curso de Matemática proporciona caminhos para que o profissional esteja apto a lecionar e, com isso, melhorar a educação nacional. Por sua vez, a grade curricular adapta-se de acordo com a necessidade, isto é, sua evolução é proporcional ao progresso do ensino. Para uma pesquisa mais direcionada, a ascensão da grade no curso de Licenciatura Plena em Matemática na Universidade Estadual do Ceará tem seu destaque, também, na formação do professor, cujo objetivo geral é apresentar a importância da disciplina História da Matemática para a formação do professor e, como objetivos específicos, mostrar a evolução da matriz curricular da UECE em prol da formação do professor e anunciar a importância dessa mudança para a educação matemática. O tipo de pesquisa metodológica foi descritivo e a análise do conteúdo, interpretativa. Já a fonte de pesquisa deu-se através do levantamento de material bibliográfico e documental sobre o tema, onde a coleta de dados teve como levantamento de dados qualitativa, bibliográfica e documental. Assim, através da História da Matemática e seu desenvolvimento, percebe-se quão importante é esta disciplina na formação do professor, por entender sua origem e nortear seu aperfeiçoamento para com o ensino e que, de forma contextual, no ano de 1998, houve uma separação da Matemática na área de Ciências na UECE e que somente em 2008 a disciplina História da Matemática entrou como obrigatória. Por mais que sua inclusão tenha sido, relativamente, tardia na grade curricular de Matemática, tem-se como propósito a ampliação do curso como forma de aperfeiçoar o conhecimento no caráter docente.
\end{abstract}

Palavras-chave: Formação do professor; História da Matemática; Matriz curricular.

\begin{abstract}
The Mathematics course provides ways for the professional to be able to teach and thereby improve national education. In turn, the curriculum adapts according to the need, that is, its evolution is proportional to the progress of teaching. For more targeted

1 diegolira.terrivel@gmail.com

2 joaovictor_cpm22@hotmail.com
\end{abstract}

Número Especial - IV Seminário Cearense de História da Matemática

Boletim Cearense de Educação e História da Matemática - Volume 07, Número 20, 181 - 189 (2020)

DOI: $10.30938 /$ bocehm.v7i20.2859 
research, the rise of the grade in the Full Mathematics Degree course at the State University of Ceará is also highlighted in teacher training, whose general objective is to present the importance of the History of Mathematics discipline for teacher training and, as specific objectives, to show the evolution of the UECE curriculum matrix in favor of teacher education and announce the importance of this change for mathematics education. The type of methodological research was descriptive and the content analysis was interpretive. The source of research, on the other hand, was the survey of bibliographic and documentary material on the topic, where the data collection had a qualitative, bibliographic and documentary data survey. Thus, through the History of Mathematics and its development, it is clear how important this discipline is in teacher education, as it understands its origin and guides its improvement towards teaching and that, in a contextual way, in 1998, there was a separation of Mathematics in the Science area at UECE and that only in 2008 the discipline History of Mathematics entered as mandatory. As much as its inclusion was relatively late in the curriculum of Mathematics, its purpose is to expand the course as a way to improve knowledge in teaching.

Keywords: Teacher training; History of Mathematics; Curriculum matrix.

\section{Introdução}

A história da Matemática abre um leque de oportunidades e conquistas na vida humana, oportunizando descobertas e evoluções para com o mundo. De forma gradativa, o currículo adapta-se de acordo com a situação na qual se encontra para melhorar a formação de professores, dando ênfase na Universidade Estadual do Ceará (UECE). Assim, o objetivo geral deste trabalho é apresentar a importância da disciplina História da Matemática para a formação do professor e, como objetivos específicos, mostrar a evolução da matriz curricular do curso de matemática em prol da formação do professor e anunciar a importância dessa mudança para a educação matemática.

Sabe-se a relevância da formação do professor, onde a grade curricular com sua evolução possibilita a estruturação acadêmica e, desse modo, questiona-se por que houve demora em incluir História da Matemática na grade curricular de Licenciatura Plena em Matemática na UECE?

O tema foi escolhido para entender a importância de um desenvolvimento adequado na formação do professor e, vendo isso, a relevância da disciplina da história da matemática e sua relação com a educação matemática, ou seja, a grade curricular salienta sua importância para a formação docente e mostrar a inclusão tardia desta disciplina no fluxograma, mais precisamente sua inclusão em 2008.1. 
A evolução da matriz curricular do curso de matemática da Universidade Estadual do Ceará e a formação do professor

Diego de Freitas Lira e João Victor Lima Fernandes

\section{Um breve contexto da história da Matemática}

Falar o contexto histórico da Matemática é comentar o nascimento da numeração escrita, aproximadamente, 3500 a.C. Importante entender e estudar o passado para saber como está o presente cuja finalidade é melhorar o futuro e, para isso, sua história é primordial para conhecer a evolução matemática e, consequentemente, a mudança na matriz curricular do curso de Licenciatura em Matemática na Universidade Estadual do Ceará.

Para Luchetta (2000), a numeração veio a partir da necessidade de saber a quantidade de gado existente, utilizando pedras, paus ou traços, em épocas primitivas. A data acima mencionada vem dos egípcios e babilônios, usando símbolos para representar números e, chegando ao período entre 250 a. C. e o século XVI, hindus e árabes inventaram o sistema de numeração, tendo como registro na Índia, símbolos precursores do sistema de numeração atual.

Aos poucos, tal sistema foi se propagando pela Europa, havendo padronização dos cálculos com numerais hindu-arábicos, no século XVI. Conforme afirma Luchetta (2000), "Muitos dos campos nos quais os cálculos numéricos são importantes, como a astronomia, a navegação, o comércio, a engenharia e a guerra, fizeram com que esses numerais fossem utilizados para tornar os cálculos rápidos e precisos”, isto é, a transformação que o sistema numérico proporcionou para uma nova leitura de mundo, seja para entender ou facilitar a exploração marítima, o faturamento no comércio ou a conquista de guerras. Seja qual for a finalidade, este sistema mudou o comportamento do homem.

Dando um salto para o início do século XIX, com a contribuição essencial dos trabalhos de Euler e Lagrange, no século anterior, o cálculo teve um papel de destaque. Mol (2013) informa a contribuição de Bernard Bolzano nos conceitos fundamentais do cálculo, mesmo com seu reconhecimento tardio, com o apoio do alemão Karl Weierstrass, estabelecendo definições de limite.

A história da matemática contribuiu não somente para o comportamento do homem no decorrer dos séculos, mas também para a formação da educação. Por mais que o tempo tenha um hiato no contexto histórico, é importante entender sua evolução em relação à educação. 
A evolução da matriz curricular do curso de matemática da Universidade Estadual do Ceará e a formação do professor

Diego de Freitas Lira e João Victor Lima Fernandes

\title{
Evolução da matriz curricular de Matemática na UECE
}

Antes de tornar-se um curso de Licenciatura Plena ${ }^{3}$ em Matemática, o curso passou por diversas mudanças em meados dos anos 1950, quando fazia parte da então Faculdade Católica de Filosofia do Ceará e, de acordo com o site da própria instituição (2019), houve uma crise financeira na faculdade e o Governo assumiu a responsabilidade, passando a chamar de Faculdade de Filosofia do Ceará e, nos anos 1970, integrou-se na Universidade Estadual do Ceará. Importante lembrar suas divisões, já que, para Monteiro et al (2016):

\begin{abstract}
Atualmente, os centros na cidade de Fortaleza estão divididos em: Centro de Estudos Sociais Aplicados CESA, (Administração, Ciências Contábeis e Serviço Social) Centro de Ciências e Tecnologias-CCT (Ciências da Computação, Física, Geografia, Matemática e Química) Centro de Ciências da Saúde- CSS (Ciências Biológicas, Educação Física, Enfermagem e Medicina) Centro de Humanidades-CH, (Ciências Sociais, Filosofia, História, Instrumento, Letras, Música e Psicologia.) Faculdade de Veterinária-FAVET (Medicina Veterinária) Centro de Educação-CED (Pedagogia). (p. 05)
\end{abstract}

No fluxograma de 1998.1 que o curso já era de licenciatura, tinham poucas disciplinas voltadas para a formação docente, priorizando disciplinas não didáticas. $\mathrm{O}$ curso apresentava uma matriz curricular com carga horária total de 2790 horas. Desse total, 600 horas compõem a formação do professor que eram distribuídas em sete disciplinas, com a Psicologia Evolutiva (60 h), Psicóloga da Aprendizagem (60h), Didática Geral I (60 h), Laboratório de Matemática (30 h), Estrutura e Funcionamento do Ensino Fundamental e Médio(60 h),sendo maior parte dessa carga os estágios obrigatórios Prática de Ensino de ciências/estágio (120 h) e a Prática de Ensino de Matemática/estágio (210 h).

No fluxograma de 2008.1, o curso ainda usava a nomenclatura Licenciatura Plena foram incluídas mais disciplinas didáticas, o curso apresentava uma matriz curricular com carga horária total de 2924 horas, sendo 12 disciplinas voltadas para a formação do docente, além das disciplinas do fluxograma anterior forma incluídas novas disciplinas História da Matemática $(68$ h) e os estágios foram divididos em seis disciplinas, Estágio Supervisionado I no Ensino Fundamental(102 h), Prática de Ensino de Matemática I (34 h), Prática de Ensino de Matemática II (34 h) Estágio Supervisionado II no Ensino Fundamenta (102 h), Estágio Supervisionado I no Ensino

\footnotetext{
${ }^{3}$ A vigente LDB,9.394/96 revogou expressamente a Lei 5.692/71 extinguindo, dessa forma, os cursos de licenciatura curta. Portanto, toda licenciatura é plena, tornando-se uma redundância tal adjetivação.
} 
A evolução da matriz curricular do curso de matemática da Universidade Estadual do Ceará e a formação do professor

Diego de Freitas Lira e João Victor Lima Fernandes

Médio (136 h), Estágio Supervisionado II no Ensino Médio(68 h), direcionando a formação do professor. Também foi incluída como optativa a disciplina Língua Brasileira de Sinais ${ }^{4}$ (LIBRAS).

Importante lembrar que, em 2008.1, a disciplina História da Matemática estava na estrutura curricular a ser cursada no $6^{\circ}$ semestre e, em analogia com a de 2019.1, a mesma disciplina estava contida no semestre anterior, ou seja, no $5^{\circ}(\mathrm{UECE}, 2019)$. E, também, neste último fluxograma, foram incluídas 19 disciplinas didáticas, priorizando o ensino docente, a própria Base Nacional Comum Curricular (BNCC) destaca a importância de conhecer aplicações tecnológicas dos conteúdos estudados. Os professores do departamento do curso que estavam envolvidos diretamente no Projeto Pedagógico do Curso (PPC) aprovado pela RESOLUÇÃO No 4352/2018 - CEPE, de 03 de dezembro de 2018, são: Prof ${ }^{\mathrm{o}}$. Thelmo Pontes de Araujo, Ph.D.; Prof ${ }^{a}$ Dra Ana Carolina Costa Pereira; Prof ${ }^{\circ}$. Dr. Tiago Caúla Ribeiro; Prof ${ }^{\circ}$. Me. Manoel Pereira Gomes Neto; Prof ${ }^{\circ}$. Dr. Claudemir Silvino Leandro.

Nesse PPC, as disciplinas forma divididas em seis áreas: Álgebra, Geometria, Analise, Matemática Aplicada, Educação Matemática e Formação docente. Essas duas últimas áreas estão mais voltadas para o ensino de matemática na educação básica. A Educação Matemática contempla as disciplinas: História da Matemática; História da Educação Matemática; Fundamentos Epistemológicos da Matemática; Tendências em Educação Matemática. Na Formação docente são: Lógica; Escrita Matemática; Psicologia da Aprendizagem; Didática Geral; Didática da Matemática; Política e Organização da Educação Básica no Brasil; Laboratório de Ensino de Trigonometria; Laboratório de Ensino de Geometria; Laboratório de Ensino de Aritmética; Laboratório de Ensino de Álgebra; Prática de Ensino de Matemática I; Prática de Ensino de Matemática II; Resolução de Problemas; Tecnologias Digitais no Ensino de Matemática; Língua Brasileira de Sinais (LIBRAS). Essas duas áreas juntas somam 19 disciplinas, além dos 4 estágios obrigatórios presentes desde o fluxograma anterior, ou seja, um total de 23 cadeiras voltadas para formação docente

\footnotetext{
${ }^{4}$ Decreto $\mathrm{N}^{\mathrm{o}}$ 5.626, de 22 de dezembro de 2005, regulamentou a Lei n. ${ }^{\circ} 10.436$, de 24 de abril de 2002, que dispõe sobre a Língua Brasileira de Sinais - LIBRAS, que será um componente curricular obrigatório nos cursos de formação de professores para o exercício do magistério, em nível médio e superior, e nos cursos de fonoaudiologia, de instituições de ensino públicas e privadas, do sistema federal de ensino. O curso de Licenciatura em Matemática de UECE só tornou a disciplina obrigatória na matriz curricular de 2019.
} 
A evolução da matriz curricular do curso de matemática da Universidade Estadual do Ceará e a formação do professor

Diego de Freitas Lira e João Victor Lima Fernandes

Nesse projeto pedagógico, a nomenclatura antiga deixou de ser utilizada, o curso é chamado de Licenciatura ${ }^{5}$ em Matemática. No gráfico 01 mostra a quantidade de disciplinas na área pedagógica do curso. E gráfico 02 mostra o percentual de disciplinas da área pedagógicas em relação ao total de disciplinas obrigatórias do curso.

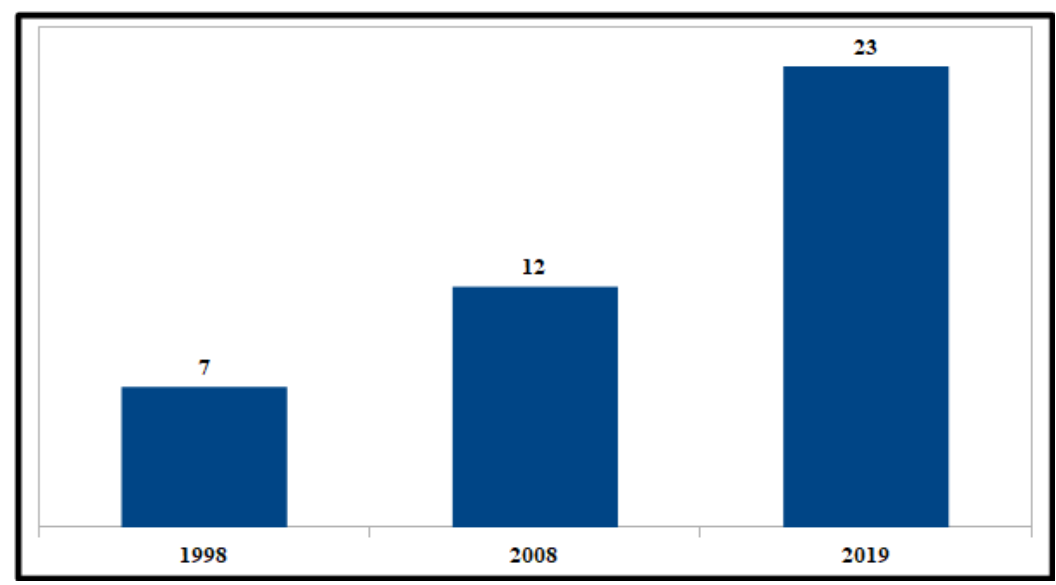

Figura 1 - Quantidade de disciplinas pedagógicas no curso de Licenciatura em

Matemática

Fonte: Elaborada pelo autor

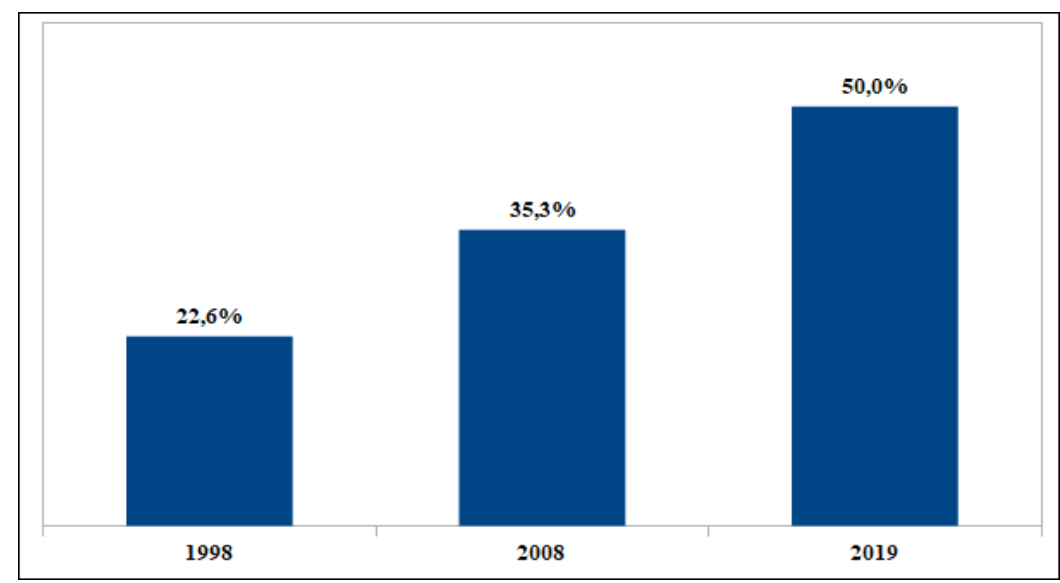

Figura 2 - O percentual de disciplinas pedagógicas no curso de Licenciatura em

\section{Matemática}

Fonte: Elaborada pelo autor

${ }^{5}$ A Nomenclatura licenciatura em plena permanece sendo utilizada por alguns cursos na plataforma da UECE, incluído o curso de matemática. Em algumas partes do site aparece a nomenclatura antiga. 
A UECE é uma universidade que tem como objetivo central a formação dos docentes. Os Projetos Pedagógicos dos cursos da Universidade, são feitos nesse sentido. Segundo Farias et al (2011):

\begin{abstract}
O projeto político pedagógico de formação de professores da Uece privilegia percursos de desenvolvimento de profissionais de educação em contexto de práxis no mundo contemporâneo, atento às peculiaridades do Nordeste e do Ceará. Fundamentado na tríplice função das instituições universitárias, em que a pesquisa privilegia a produção do conhecimento, o ensino busca ensejar a aprendizagem dos conhecimentos e saberes e a extensão constitui-se em lócus de vivência e integração dessas funções, o trabalho do profissional de educação requer a integração de uma dupla formação: no campo disciplinar, de conhecimentos de sua área específica de ensino; no campo do "saber ensinar", de conhecimentos teóricos e práticos que possibilitem a mediação pedagógica de aprendizagem ao saber. Esse postulado determina, portanto, uma dupla competência. (p. 6).
\end{abstract}

Percebe-se que o curso de Licenciatura em Matemática vem-se direcionando cada vez mais para a formação do professor, fazendo com que haja uma mudança na estrutura curricular no quesito didático incluindo mais disciplinas pedagógicas, e que disciplinas não didáticas voltadas para o cálculo estejam também no fluxograma, sem desmerecer suas importâncias, pois o educador precisa do conhecimento de ambos.

\title{
A disciplina História da Matemática na formação do professor
}

A matriz curricular proporciona ao aluno, conforme dito anteriormente, opções de conhecimento e, em especial a disciplina História da Matemática mostra, para Oliveira et al (2014, p. 459) “é um instrumento de investigação, das origens e descobertas, métodos e notações matemáticas que foram desenvolvidas ao longo do tempo, desde as antigas civilizações até os dias de hoje.".

A forma como se conhece a matemática hoje foi modificada ao longo do tempo, por exemplo, não havia o símbolo 0 (zero), já que em algumas civilizações deixavam um espaço vazio para representá-lo (ex. $101=1$ 1). O estudo da história da matemática ajuda a compreender a construção das noções básicas dos conceitos matemáticos, cuja finalidade é apresentar ao aluno vivências do dia a dia, através de problematizações, questionamentos e resultados, desenvolvendo o raciocínio lógico-matemático.

Para Oliveira et al (2014), reconhecer esse processo histórico é compreender as ideias e modificações culturais que a sociedade vivenciou, relacionando-se com o cotidiano do aluno. Assim, 
O uso dos fatos históricos na sala de aula proporciona um melhor entendimento dos alunos no que diz respeito à dimensão histórica dos assuntos envolvidos, despertando assim o interesse dos alunos, motivando-os ainda mais a buscar o conhecimento. O professor precisa despertar nos alunos o aspecto investigativo para que ele próprio busque alternativas para resolver problemas, propiciando assim que os alunos desenvolvam o senso crítico, colaborando para que, se forme cidadãos mais críticos e conscientes do seu papel na sociedade contemporânea, o que faz com que se tenha uma possibilidade mais evidente de êxito na construção do conhecimento. (OLIVEIRA et al. p. 460)

Por mais que tenha tido uma demora na inclusão desta disciplina no fluxograma da UECE no curso de Matemática, o crescimento docente aparece de forma gradativa para que mostre aos discentes uma didática aplicada ao cotidiano, mesclando com cálculos, sem perder sua qualidade, sabendo lecionar e conhecendo o que leciona.

\section{Referências}

BRASIL. Decreto No 5.626, de 22 de dezembro de 2005 que regulamenta a Lei n. $^{\circ}$ 10.436, de 24 de abril de 2002, que dispõe sobre a Língua Brasileira de Sinais LIBRAS. Diário Oficial da República Federativa do Brasil, Brasília, 23 dez. 2005. Disponível em: < http://www.planalto.gov.br/ccivil_03/_Ato2004-2006/2005/Decreto /D5626.htm >. Acesso: 20 fev 2020.

BRASIL. Lei n. 9.394, de 20 de dezembro de 1996. Estabelece as diretrizes e bases da educação nacional. Disponível em<http://www.planalto.gov.br/ccivil_03/LEIS/L9394. htm> Acesso em 20 fev de 2020.

CEARÁ. Resolução n 4352/2018 - CEPE, de 03 de dezembro de 2018.que aprova a atualização do Projeto Pedagógico do curso Licenciatura em Matemática /CCT.Fortaleza-CE. Disponível em<http://www.uece.br/wp-content/uploads/2019/04/ RES-4352-CEPE.pdf > Acesso em 20 de fev 2020.

FARIAS, Isabel Maria Sabino de; THERRIEN, Jacques; NÓBREGA-THERRIEN, Silvia Maria; SALES, José Albio Moreira de. Formação de Professores: A responsabilidade social da Universidade Estadual do Ceará. Revista Educação Brasileira-CRUB2011. Disponível em: < http://jacquestherrien.com.br/wpcontent/uploads/2014/06/Formação-de-Professores-a-Responsabilidade-Social-daUECE.pdf > Acesso em: 19 fev. 2020.

LUCHETTA, Valéria Ostete Jannis. Antigo sistema de numeração. Disponível em: <http://www.matematica.br/historia/numeracao.html> Acesso em $12 \mathrm{dez} 2019$

MOL, Rogério S., Introdução à História da Matemática. Disponível em: < http://www.mat.ufmg.br/ead/wpcontent/uploads/2016/08/introducao_a_historia_da_mat ematica.pdf > Acesso em $12 \mathrm{dez} 2019$ 
A evolução da matriz curricular do curso de matemática da Universidade Estadual do Ceará e a formação do professor

Diego de Freitas Lira e João Victor Lima Fernandes

MONTEIRO. Rachel Rachelly Matos et al. História dos cursos de Licenciatura da Uece. III Congresso Nacional de Educação. Disponível em: < http://www.editorarealize.com.br/revistas/conedu/trabalhos/TRABALHO_EV056_MD1 _SA4_ID901_09082016183520.pdf> Acesso em 12 dez 2019.

OLIVEIRA, Vanessa Castro de et al. A história da matemática e o processo de ensino aprendizagem. XX Encontro Regional de Estudantes de Matemática da Região Sul, 2014. Disponível em:

<https://eventos.unipampa.edu.br/eremat/files/2014/12/PO_oliveira_00971876070.pdf> Acesso em 14 dez 2019.

SAKAMOTO, Cleusa K.; SILVEIRA, Isabel O. Como fazer projetos de iniciação científica. São Paulo: Paulus, 2014.

UECE - Universidade Estadual do Ceará. Curso de Matemática da Uece completa 66 anos. Disponível em: < http://www.uece.br/noticias/curso-de-matematica-da-uececompleta-66-anos/> Acesso em $13 \mathrm{dez} 2019$.

UECE - Universidade Estadual do Ceará. Grade de curso. Disponível em: <http://www.uece.br/prograd/index.php/cursos-de-graduacao/presenciais > Acesso em 13 dez 2019.

UECE - Universidade Estadual do Ceará. Projeto Pedagógico do Curso de Licenciatura Plena em Matemática. Fortaleza: UECE, 2007.

UECE - Universidade Estadual do Ceará. Projeto Pedagógico do Curso de Licenciatura Plena em Matemática. Fortaleza: UECE, 2018. 